\title{
Deploying Technology-Enhanced Learning Environments in Tanzanian Secondary Schools
}

\author{
Tabu S. Kondo \\ Computer Technologies and Applications \\ The University of Dodoma \\ Dodoma, Tanzania
}

\author{
Leonard J. Mselle \\ Computer Science \\ The University of Dodoma \\ Dodoma, Tanzania
}

\begin{abstract}
In this paper we describe how technology can be combined with face-to-face method to facilitate teaching and learning various subjects in Tanzanian secondary schools. A smart school model is proposed. The model consists of students, teacher/facilitator/digital content expert and digital content delivery vehicles that can be implemented in a learning environment in which technology plays a subordinate role and serves to enrich the traditional face-to-face classroom.
\end{abstract}

\section{General Terms}

Education, Technology

\section{Keywords}

Smart School, TEL, Digital Content, Offline M-Learning

\section{INTRODUCTION}

Many educators would agree that a vital indicator of student success is students' ability to develop both skills and an interest for lifelong learning. If this is the objective, then it follows that the modes of teaching employed and the overall educational experience and environment should reinforce these objectives [1]

The emerging student technology-learning mode is exactly the kind of fast paced lifelong learning and collaboration skill set that is demanded by our rapidly changing world. It is a mode of transient learning where expertise in areas that become rapidly obsolete is less valued than the ability to quickly master emerging knowledge. Disciplinary knowledge is also being made irrelevant by the demands for multi and interdisciplinary learning skills [1].

\subsection{Technology-Enhanced Learning}

Technology-enhanced learning (TEL) refers to the use of Information and Communication Technologies (ICTs) to support and enhance teaching and learning processes. TEL environments enable access to a range of materials, learning tools and communication facilities, so that they can create ideal constructivist learning environments that enable the students to become more actively involved in developing their understanding. From a constructivist perspective, a learning environment can be defined as 'a place where people can draw upon resources to make sense out of things and construct meaningful solutions to problems [2].

\section{ADVANTAGES OF TEL}

\subsection{From a teacher's point-of-view}

From a teacher's point of view [3], technology-enhanced learning can:

- Help to manage and organize course materials more effectively and efficiently.
- $\quad$ Reduce the need for certain administrative tasks (for example, making paper copies, marking tests, giving out course reminders)

- Enable monitoring of student participation and progress, ensuring that lecturers can offer directed support and advice quickly and can make more effective use of staff-student contact time.

- Widen communication opportunities between lecturers and students.

- Help to change the teacher's role from "knowledge provider" to "learning facilitator", promoting selfdirected learning.

- $\quad$ Reduce large-group teaching and increase time spent with small groups or individuals.

- Encourage the development of flexible learning materials.

\subsection{From a student's point-of-view}

From a student's point of view [4], technology-enhanced learning has the following advantages:

- Increased understanding: animations, simulations and videos can all be used to demonstrate something that is hard to understand from explanations in words or on paper.

- Facilitate student-centered learning: students can participate in online course activities when and where is best for them.

- Reinforcing learning: online resources allow students to revisit or go over challenging material at their own pace and as often as they require.

- Immediate feedback: computer quizzes are enjoyed by many students. They can provide immediate feedback, which can also be tailored and/or anonymous if appropriate.

\section{DISADVANTAGES OF TEL}

Technology-enhanced learning has the following disadvantages [4]:

- Reliability: although most systems are now pretty robust, no technology is ever $100 \%$ reliable. Some technologies, especially things that are very new (avoid version 1.0 of most software!) can be subject to frustrating errors. Have a backup plan if you have any concern about reliability.

- Maintenance time: all systems require maintenance from time to time, although hopefully this will be scheduled and advertised.

- Pace of change: technology is a fast changing field. Software can quickly become out of date, or be replaced by later versions with enhanced functionality. One will almost certainly have to keep adapting and updating.

\section{SMART EDUCATION IN KOREA}

The Korean government announced the plan for SMART Education in 2011. According to the government report [5], 
SMART Education is defined as "intelligent and adaptive teaching and learning system to enable new pedagogy, curriculum, assessment, teacher, etc. which are required for the $21^{\text {st }}$ century knowledge society; learning format which is integrating social learning and adaptive learning in the best communication environment".

Each letters of the word, SMART, represents the concept of SMART Education. That is; ' $S$ ' stands for 'Self-directed' learning which makes class time flexible through just-in-time learning in online learning. ' $\mathrm{M}$ ' is used to abbreviate 'Motivated' learning which is related to educational methods such as collaborative learning and experiential learning. The letter 'A' stands for 'Adaptive' learning which is focusing on individualized learning according to students' competencies. The letter ' $R$ ' stands for 'Resource-enriched' learning which is related to educational contents to support students' problem-solving skills and creativity. Lastly, the letter ' $\mathrm{T}$ ' represents 'Technology-embedded' learning which is supporting the expansion of learning spaces into home and communities through cutting-edge technologies. In summary, SMART education is a comprehensive approach to $21^{\text {st }}$ century society, not limited to technology-oriented focuses [5].

\section{THE MALAYSIAN SMART SCHOOL CONCEPTUAL MODEL}

The Ministry of Education of Malaysia started to conceptualize the Malaysian Smart School in 1996, under the leadership of the then Director-General of Education, Tan Sri Dato' Dr. Wan Zahid Wan Mohamed. The conceptualized document entitled "The Malaysian Smart School: A Conceptual Blueprint" [6] explains that the Malaysian Smart School concept is derived from best practices from around the world, as well as from the best home-grown practices of teachers and educators in Malaysia. In essence, the Malaysian Smart School is defined as:

“... a learning institution that has been systematically reinvented in terms of teaching-learning practices and school management in order to prepare children for the Information Age. A Smart School will evolve over time, continuously developing its professional staff, its educational resources, and its administrative capabilities. This will allow the school to adapt to changing conditions, while continuing to prepare students for life in the Information Age. To function effectively, the Smart School will require appropriately skilled staff and welldesigned supporting processes " [6].

\section{PROBLEM DEFINITION}

The secondary school education system in Tanzania is ineffective, as reflected in the chronic poor performance of secondary school students. For example, in the academic year 2012/2013 only 43.08\% [7] of Form Four students passed the Form IV (Ordinary level) Secondary School Examinations. Despite the nearly ubiquitous access to mobile phones technology in Tanzania, there is a significant gap between the presence of technology and its use in the classroom. Furthermore, there is no evidence of massive effort to use the available technology to improve secondary school education in Tanzania. To solve this problem, we propose a model for making Tanzanian Secondary schools smarter by redesigning them to combine the available technology with face-to-face learning approach to improve teaching and learning. The proposed model is an attempt to evolve a model for using available technology to improve education delivery in Tanzanian secondary schools by improving availability of learning materials to students and complementing face-to-face class sessions through offline digital content.

\section{OBJECTIVES}

In this research we focused in the following objectives:

i. To propose a possible SMART school model based on the current circumstances in Tanzania.

ii. To explore the effectiveness of the proposed SMART school model in Tanzania.

\section{RESEARCH QUESTIONS}

i. Which is the effective way of integrating ICT in teaching and learning various subjects in Tanzanian secondary schools?

ii. To what extent can ICT facilities enhance teaching and learning in Tanzanian secondary schools in their current setting?

\section{THE PROPOSED SMART SCHOOL MODEL}

The SMART school model as proposed in Figure 1 is a threelegged stool resting on the student, the teacher/facilitator/digital content expert and the technology (ICT) that delivers digital content. This combination revolves on a digital content developed by a subject expert who depends on the technology to reach to students. The technology infrastructure is expected to serve fundamentally as an enabler in the proposed model, revitalizing and refreshing practice in teaching and learning. The technology employed within the smart school infrastructure involves the integration of hardware, software, system software and non-IT related equipment running in both local and in a wide area network. The model is conceived by borrowing some elements from Korean [5] and Malaysian [6] experience.

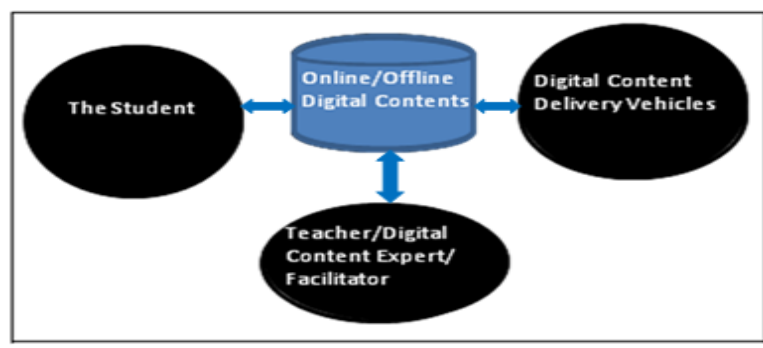

Fig 1: The proposed smart school model for Tanzanian secondary schools

\subsection{The Students}

ICT increases the student's involvement and motivation in the learning process. Jones, Jo and Crantich [8] suggest that proficiency in computer-based multimedia is an important skill to students who use the Internet on a fairly regular basis. However, Mselle and Kondo [9] found that computer skills do not constitute an imperative condition for students to use offline digital contents for their studies. There is growing evidence that digital lectures can be just as useful as face-toface lectures if the environment is created. Since the digital content delivered offline is useful as that delivered online, internet connectivity and internet related skills are not a necessary condition for a student to use the model. 


\subsection{Digital Teacher, the Subject Expert and the Facilitator}

In an ideal situation, the smart school model depends on a digital teacher, aided by a teacher who is an expert of the subject and a facilitator who is not necessarily required to be expert in neither the field of ICT nor the subject matter that he/she is supposed to facilitate. If circumstances do not permit, the digital content can be delivered without a facilitator or a subject expert.

\subsection{Digital content delivery vehicles (The ICT)}

Computers, televisions and mobile telephones are the primary delivery vehicles for digital contents. Peripherals such as CDROMs, DVDs and DVD players can be used for offline delivery. The smart school model, under ideal conditions includes the intranets and internet connectivity, and even satellite and web broadcasts of classes and conferences, mobile phones, other handheld devices (e.g. PDAs, MP3 players, i-pods, digital audio recorders, and digital video recorders), games consoles, TV and radio. In case the conditions are far from ideal, offline digital content can be used to replace online digital content, with and without teachers and in some cases without facilitators.

\section{THE EFFECTIVENESS OF USING SMART SCHOOLS}

The integration of technology into teaching is viewed in the perspective of instruction through information delivery [8]. It employs all of the technological capabilities to deliver animations, text, audio, video as well as computer assisted instruction (CAI) to enhance learning.

It is believed that using new technology for learning may enhance the students' learning interest and motivation since it is easy to use and enables students to learn within or outside the classroom [10].

According to Ong and Ruthven [11] the most distinctive feature of the smart school is the teaching and learning environment that builds on best practices from around the world. This includes the mutually reinforcing and coherent alignment of four different dimensions, namely the curriculum, pedagogy, assessment and teaching -learning materials.

Ong and Ruthven [12] conducted a study on secondary school students in science subjects and found that form 3 students involved in the 3-year smart school initiative had a significantly higher adjusted mean score compared to students involved in the mainstream program. Accordingly, in terms of impact, the results indicated that students in the smart schools have significantly more positive attitudes towards science than their counterparts in the mainstream schools.

\section{THE STUDY SETTING}

\subsection{The digital content}

The digital video content was made pursuant to requirements by NECTA [13] using lectures adapted from Toner [14] and Sousa [15] as directed by MoEVT [16]. These materials were recorded in English language which is the language used in Tanzanian secondary schools. The materials were then stored in memory cards of the smart phones. The content covered the entire Form I, II, III and IV syllabi according to MoEVT [16].

\subsection{The students and their participating parents}

Fifteen students were involved in the study. Eight of the students were female and the remaining seven were males. All of them were pursuing Form I secondary studies in seven different schools. All of them were computer illiterate. Their families could be classified as Tanzanian middle class families. Ten of the parents were civil servants (seven employed as primary school teachers and three are small farmers). All these families possessed smart phones. Eight of the participating parents were males and two were females. Only three families had personal computers but these were not for children access. The choice of these families was purposeful, targeting Form I secondary school students with mathematics as their subject of study. Students and parents willfully volunteered to participate in the study.

The parents and their children were approached by researchers and a briefing on the study was given to each. Each family was approached separately from the other. One important condition was for the parent(s) to agree to encourage the student to pursue self revision classes through recorded digital video classes by using smart phones. Each parent and student were given a sheet for recording hours that the student would spend in revising mathematics lessons in digital video format and hours that the student would spend for self study using books and notes. This revision was carried out during students' long vacations. In addition to study hours, parents and students were requested to avail the researchers with the students' scores in any previous test and scores in the test that students would attempt after the vacation.

\section{RESULTS AND DISCUSSION}

\subsection{Self study hours, test scores and necessity for basic computer skills}

One objective was to find out how students' self study interest would be affected by offline M-Learning approach as a complement to their lecture notes and books. Three weeks after offline M-Learning approach was introduced, records concerning study patterns by hours within the period were obtained. Students and parents contributed on reporting the difference in hours between that a student would usually spend revising without digital video lessons and hours the student spent on revision using digital video content. Pretest and posttest results collected in a period of one month are summarized in table 1.

The students reported to have revised five to eight topics of mathematics. Among those which were revised by all students includes; numbers, units, approximations, geometry and algebra. Statistical data on the results are summarized in table 1. The offline M-learning approach led to significantly more positive attitudes toward mathematics, $\mathrm{t}(14)=-4.4997, \mathrm{p}=$ .0002 , one-tailed.

Regarding hours of study, all students reported to have increased self study time by an average of 8 hours in a period of three weeks during vacation. Although one reason for the increase of time was obviously the itch for using the new approach, the time record showed that students were more comfortable with digital video content approach than book/notes reading. These results are in line with findings by Bassili [17] who concluded that students preferred digital lectures to face-to-face approach. 
Table 1. Summary of pretest and posttest results

\begin{tabular}{|c|c|c|}
\hline \multirow{2}{*}{ t-Test: Paired Two Sample for Means } \\
\hline & Pretest & Posttest \\
\hline Mean & 55.53333333 & 61.2666667 \\
\hline Variance & 498.8380952 & 554.495238 \\
\hline Observations & 15 & 15 \\
\hline $\begin{array}{c}\text { Pearson } \\
\text { Correlation }\end{array}$ & 0.978247222 & \\
\hline $\begin{array}{c}\text { Hypothesized } \\
\text { Mean Difference }\end{array}$ & 0 & \\
\hline df & 14 & \\
\hline t Stat & -4.49968495 & \\
\hline P(T<=t) one-tail & 0.000249747 & \\
\hline $\mathrm{t}$ Critical one-tail & 1.761310115 & \\
\hline $\mathrm{P}(\mathrm{T}<=\mathrm{t})$ two-tail & 0.000499493 & \\
\hline $\mathrm{t}$ Critical two-tail & 2.144786681 & \\
\hline
\end{tabular}

Regarding students' performance, the results did show significant statistical difference. The mean score for posttest is greater than the mean score for pretest. Furthermore, the calculated $t$ statistic of -4.4997 indicates that the posttest score is significantly higher than the pretest score. Therefore, it can be concluded that offline M-Learning method was effective in Tanzanian context.

The study confirms that basic computer knowledge is not a prerequisite condition for effective deployment of offline MLearning. Deployment of video content in smart phones has no relationship with basic computer skills. This is a very serious observation because more investment is being directed towards basic computer skills instead of immediate use of offline M-Learning for delivery of the digital video content. Offline M-Learning proves to be an acceptable method to the majority of the students and parents.

\section{CONCLUSION AND RECOMMENDATIONS}

New technologies have changed teaching and learning in a number of ways- from graphing calculators to online lesson plans to virtual field trips and simulated dissections. Educational technologies can help students to access content in new and often exciting ways.

Digital content has become a part of students' daily life due to the dissemination of digital technology, due to the continuous emergence of new technology, more and more students want to use hi-tech electronic devices for learning. Technology can be used to support learning activities in and out of school in both formal and informal situations.

The use of technology enable students to collect and interact with the resources such as images and video and encourage communication and collaboration, hence technology has great potential of engaging learner [18].

We have proposed a smart school model that provides Tanzanian secondary schools a strategy for integrating emerging technologies into the classroom. The model is grounded in student learning and may be applied to any technology. We presented the model alongside examples from Malaysians [6] who have used smart schools to incorporate technology into their classrooms.

The smart school model proposed in this paper combines the concept of offline and online digital content and M-learning as it was suggested by Mselle and Kondo [9], [19]; mixing the Malaysian model as presented in [6]. Therefore, online or offline digital contents delivered through various digital content delivery vehicles such as computers, televisions and mobile phones can be used in parallel to complement face-toface approach so as to overcome the problem of books and teachers in Tanzanian secondary schools.

Mobile phones use in Tanzanian secondary schools is not allowed to students. We propose for special mobile phones, blocked from general internet access for students to use for their learning outside classrooms.

This study did not venture into the optimal balance of the components of the model. Future work will focus on investigating the optimal balance under different circumstances and the best techniques and tools for implementing digital content rights management so as to improve the security of the digital content.

\section{ACKNOWLEDGMENTS}

We would like to express our appreciation to the Management of the College of Informatics and virtual education of the University of Dodoma for their moral support.

\section{REFERENCES}

[1] Smirnova, L. 2008 Technology Enhanced Teaching and Learning for Student (and Teacher) Success. Retrieved at http://www.nyu.edu/frn/publications/defining.success/S mirnova.html on $9 / 9 / 2013$.

[2] Wilson, B.G. 1996 What is a constructivist learning environment? In B. G. Wilson (Ed) Constructivist learning environments: case studies in instructional design (pp. 3-8). Educational Technology Publications.

[3] Benefits of technology enhanced learning. Retrieved at http://www.nottingham.ac.uk/teaching/resources/abouttechnology-enhanced-learning/benefits-of-technologyenhanced-learning.aspx on 10/9/2013.

[4] Technology enhanced learning. Retrieved at http://www.ed.ac.uk/schools-departments/instituteacademic-development/learningteaching/staff/advice/gettingstarted/technology-learning on $9 / 9 / 2013$.

[5] Ministry of Education, Science and Technology. 2011 Promotion strategy for SMART education. Policy Report.

[6] Smart School Project Team. 1997a Smart school flagship application: The Malaysian smart school - A conceptual blueprint. Kuala Lumpur. Ministry of Education.

[7] Ministry of Education and Vocational Training (MoEVT). Details for TAARIFA YA MATOKEO YA MITIHANI K4 2012. Retrieved at http://www.moe.go.tz/index.php?option=com_docman\&t ask $=$ doc_details $\&$ Itemid $=0 \&$ gid $=212$ on $9 / 8 / 2013$.

[8] Jones, V. Jo, J. and Crantich, G. A study of students' responses to WBI within a traditional learning environment. The sixth Australian World Wide Web 

Conference. Available online at:
http://ausweb.scu.edu.au/aw2k/papers/jones/paper.html. Site visited on 9/8/2013.

[9] Mselle, L. J. and Kondo, T. S. 2012 Deploying Computer-Based Learning under Suboptimal Conditions. International Conference on Internet Technology and Secure Transactions (ICITST). Heathrow. London. UK.

[10] Inan, F. A. and Lowther, D. L. 2010 Factors affecting technology integration IN K-12 classroom: a path model. Educational technology research and development. vol 58(2) $137-154$

[11] Ficheman, I. K. and Lopes, R. D. 2008 Digital learning ecosystems: authoring, collaboration, immersion and mobility. IDC proceedings. Doctoral consortium. Chicago. IL. USA ACM.

[12] Ong, T. and Ruthven, K. 2009 The effectiveness of smart schooling on students attitudes towards science. Eurasia Journal of Mathematics, Science \& Technology education. 5(1), 35-45.

[13] The National Examinations Council of Tanzania (NECTA). 2010 Mathematics Curriculum for Tanzania Ordinary Level Secondary Schools. Tanzania.
[14] Tonner, S. www.MathVideos.Net.

[15] Sousa, J. http://www.phoenixcollege.edu.

[16] Ministry of Education and Vocational Training (MoEVT). 2010 Basic Mathematics Syllabus for Secondary Schools. Form 1-IV.

[17] Bassili, J. N. 2006 Promotion and Prevention Orientations in the Choice to Attend Lectures or Watch Them Online. Journal of Computer Assisted Learning 22: pp. $444-455$.

[18] Gillespie, B. Influence of pre-service teachers preparedness to use Information and Communication Technology in classroom, where are you in landscape of educational technology? Retrieved from www.ascilite.org.au/conference/mebourne/pwcs/gill.pdf on $24^{\text {th }}$ April 2013

[19] Mselle, L. J. and Kondo, T. S. 2013 Results on Delivering Offline e-Learning Using Domestic Televisions. Fifth International Conference on Internet Technologies and Applications. Wrexham. North Wales. UK. 